\title{
ПЕРСПЕКТИВНЫЕ РАСЧЕТЫ НАСЕЛЕНИЯ В ГЕРМАНИИ
}

\section{ОЛЬГА ПЁТЧ}

\begin{abstract}
Целенаправленная социально-экономическая политика немыслима без представлений о будущем развитии населения и его структуры. Перспективные расчеты населения позволяют получить такого рода компас. Их результаты показывают, как будут изменяться численность и структура населения при определенных гипотезах о развитии рождаемости, смертности и миграции. Поскольку эти демографические проиессы протекают очень постепенно и их воздействие проявляется в полной мере лишь через несколько десятилетий, особый интерес представляют расчеты на долгосрочную перспективу.
\end{abstract}

\begin{abstract}
Данная статья знакомит с официальными перспективными расчетами населения Федерального статистического управления Германии. Опираясь на широко распространеннье в международной практике когортно-компонентный метод и сценарную технику, они имеют ряд особенностей. Как трактовка ичелей и интерпретация результатов, так и некоторые детали методологии, и дизайн сиенариев как системы равноченных вариантов будущего развития отличны от принятых в настоящее время в России. На примере предположений 13-го координированного перспективного расчета о будущей динамике рождаемости статья знакомит с одним из возможных подходов $к$ моделированию гипотез. В основе этого подхода находится анализ тенденций динамики репродуктивного поведения женщин реальных поколений. В заключение сделанные на базе данных 2013 г. выводы о будущем уровне итоговой рождаемости критически анализируются с учетом новых данных до 2016 г. о подъеме деторождения в Германии. Анализ факторов, сопутствуюших этому проиессу, позволяет оценить их потенциал для будущчего развития рождаемости.
\end{abstract}

Ключевые слова: демографические прогнозы, когортно-компонентный метод, прогнозные гипотезы, рождаемость, средний возраст матери, откладывание рождений, компенсация рождений, коэффициент суммарной рождаемости, итоговая рождаемость.

\section{ВСТУПЛЕНИЕ}

Прогнозы или, точнее, перспективные расчеты населения - исключение в сфере официальной статистики. Присущая будущему неопределенность противоречит свойственному государственной статистике стремлению к максимально точному учету. Демографические прогнозы являются, однако, инструментом, без которого общество было бы лишено важного компаса и перспективная социально-экономическая политика была бы невозможна. Как в России, так и в Германии, о которой здесь пойдет речь, они привлекают пристальное внимание различных групп пользователей и нередко подвергаются критике самого разного калибра. Главной ее причиной служат, как правило, завышенные ожидания в отношении точности «предсказания» реального развития. Поэтому для грамотного использования перспективных расчетов важно понимание как их возможностей, так и их ограниченности.

ОЛЬГА ПЁТч (olga.poetzsch@destatis.de), ФЕДЕРАЛЬНОЕ СТАТИСТИЧЕСКОЕ УПРАВЛЕНИЕ ГЕРМАНИИ, ФРГ.

СТАТЬЯ ПОСТУПИЛА В РЕДАКЦИЮ В ДЕКАБРЕ 2017 Г. 
Статья знакомит с официальными перспективными расчетами населения Федерального статистического управления Германии (далее ФСУ). При схожих с применяемыми в России методах расчета и поиска гипотез они отличаются трактовкой целей и интерпретацией результатов, а также некоторыми деталями методологии и дизайном вариантов. Этим особенностям посвящены первые три раздела. Поскольку в рамках одной статьи невозможно уделить одинаковое внимание всем гипотезам, в четвертом разделе рассматривается один из подходов к формированию предположений на примере рождаемости. Данный пример интересен, во-первых, потому что в основе предположений о рождаемости ФСУ Германии лежит не только широко применяемая формальная экстраполяция тренда коэффициентов рождаемости, но, в первую очередь, демографический анализ репродуктивного поведения реальных поколений. Это дает возможность российскому читателю познакомиться с альтернативными подходами к обоснованию гипотез рождаемости. Во-вторых, ввиду необычно сильного отклонения реальных тредов рождаемости в 2014-2015 гг. от предположений последнего перспективного расчета населения на базе данных до 2013 г., интересно проанализировать, в какой степени эти актуальные изменения влияют на новые гипотезы о долгосрочных тенденциях в рождаемости.

\section{1. ЦЕЛИ И ПРИНЦИПЫ ОФИЦИАЛЬНЫХ ПЕРСПЕКТИВНЫХ РАСЧЕТОВ НАСЕЛЕНИЯ ГЕРМАНИИ}

В международной практике демографических прогнозов большое внимание уделяется терминологии. Это облегчает общение с пользователями, журналистами, оппонентами и коллегами из других стран. ФСУ Германии проводит и публикует так называемые Координированные перспективные расчеты населения. «Координация» касается подготовки гипотез и методологии расчетов на региональном и федеральном уровнях. Это является условием сопоставимости результатов по федеральным землям и по Германии в целом.

Понятию «перспективный расчет» (англ. projection, нем. Vorausberechnung) отдаётся предпочтение перед понятием «прогноз» (англ. forecast, нем. Prognose). Понятие «прогноз» используется крайне редко как обобщающий термин. Поскольку «прогноз» ассоциируется с чем-то предсказуемым или запланированным, то это понятие более адекватно для краткосрочных расчетов ${ }^{1}$. Демографические же модели на длительную перспективу - как бы основательно они ни были продуманы и просчитаны - всегда условны: они показывают, как будут развиваться половозрастная структура и численность населения в случае протекания демографических процессов в соответствии с принятыми гипотезами ${ }^{2}$. В этом имманентная ограниченность и в то же время большие преимущества перспективных расчетов при условии, что они научно обоснованы и объективны.

\footnotetext{
${ }^{1}$ Краткосрочные демографические прогнозы не менее важны, но они относятся к иной категории моделей и пока не разрабатываются федеральной статистикой.

2 Для сравнения: Архангельский и Елизаров трактуют демографический прогноз как «научно обоснованное предвидение будущей демографической ситуации» [Архангельский, Елизаров 2016].
} 
Воздействие демографических процессов на численность и структуру населения проявляется в полной мере лишь по прошествии нескольких десятилетий. С целью дать как можно более полную картину развития населения в будущем ФСУ Германии проводит перспективные расчеты на долгосрочный период от 40 до 60 лет. При этом приходится считаться с тем, что с увеличением прогнозного периода неизбежно усиливается гипотетический характер сделанных предположений.

При проведении долгосрочных перспективных расчетов речь, однако, не идет о том, чтобы «предвидеть» или «предсказать» точную цифру на тот или иной год. Более реальной, но не менее существенной, является верная оценка средне- и долгосрочных последствий протекающих или назревающих демографических изменений. В контексте современного развития Германии это относится в первую очередь к темпам старения населения, изменению соотношения между группами населения в трудоспособном и нетрудоспособном возрастах, а также к неравномерности развития регионов. Как показывает ретроспективный анализ отклонений прогнозных расчетов за период с 1997 по 2009 г. от реального развития, эту функцию они выполняли до сих пор надежно [Рötzsch 2016a].

Это позволяет, с одной стороны, подготовить общественность к практически неизбежным (при последовательном развитии) феноменам, таким, например, как резкое повышение численности людей в возрасте старше 80 лет. С другой стороны, это даёт возможность вовремя распознать негативные тенденции и принять меры, препятствующие их распространению или смягчающие их последствия.

В Германии одним из примеров такой реакции государства на результаты перспективных расчетов является постепенное повышение пенсионного возраста с 65 до 67 лет с 2012 по 2031 г. В этот период многочисленное поколение беби-бума (с конца 1950-х до конца 1960-х годов) выйдет из работоспособного возраста, а его место займут сравнительно малочисленные более молодые когорты. Постепенная передвижка пенсионной границы позволит сделать этот переход менее резким для систем социального страхования и уменьшить диспропорции между группами населения в работоспособном и пенсионном возрастах [Rürup-Bericht 2003]. Помимо пенсионной реформы, реакцией на перспективные расчеты населения стали также мероприятия семейной политики 2007-2014 гг. (см. раздел 4.4) и обширная дискуссия о низкой рождаемости, высокой бездетности и проблемах работающих родителей ${ }^{3}$.

Таким образом, цель официальных перспективных расчетов населения в Германии заключается прежде всего в том, чтобы своевременно и верно проанализировать возможные последствия протекающих демографических изменений и подготовить информационную базу для политики, экономики и общества. Если такая система предупреждения и реакции

\footnotetext{
${ }^{3}$ Оценка демографической тенденции как «негативной» или «позитивной» делается, как правило, исходя из приоритетов данного времени. При выборе превентивных мер не всегда могут быть учтены все их возможные последствия, в том числе и негативные. Например, «политика одного ребенка» в Китае, введенная с целью ограничения роста населения, достигла своей приоритетной цели. Но одновременно она породила новые демографические проблемы: сильное старение населения и сверхпропорциональный рост доли мужского населения.
} 
на предупреждение функционирует, то отклонение реального развития населения от прогнозной модели вследствие целенаправленной демографической политики является желаемым результатом.

Чтобы перспективные расчеты могли выполнить свою сигнальную функцию, им должен предшествовать верный анализ исходной демографической ситуации, а также долговременных и текущих тенденций в рождаемости, смертности и миграции.

В Германии проведение перспективных расчетов населения предписывается Законом о статистике населения [Bevölkerungsstatistikgesetz 2015: §5]. ФСУ придает большое значение соблюдению принцииов нейтральности, объективности, научной обоснованности и доступности, лежащих в основе германской официальной статистики. В обсуждении гипотез принимают участие только специалисты: группа экспертов из 7-10 членов (видные учёные и представители организаций, занимающихся прогнозированием) и представители земельных статистических управлений. Гипотезы и результаты нового перспективного расчета представляются президентом ФСУ на пресс-конференции для журналистов и публикуются на сайте для всех заинтересованных пользователей [Statistisches Bundesamt 2015a].

Первый прогнозный расчет был осуществлен в ФРГ в 1951 г. Координированные перспективные расчеты проводятся с 1966 г. Последний 13-й координированный расчет развития населения с 2014 по 2060 г. был опубликован в начале 2015 г. Один из его вариантов был актуализирован в начале 2017 г. с учетом изменений в результате беспрецедентного притока иммигрантов в 2015 г. Подробнее об этом сказано в разделе 3.

\section{2. МЕТОДОЛОГИЯ РАСЧЕТОВ И ИСХОДНАЯ ИНФОРМАЦИЯ}

Прогнозные модели ФСУ Германии основаны на когортно-компонентном методе. В России этот метод больше известен как „метод передвижки возрастов“. Этот подход возник в Англии и Уэльсе в конце XIX века [Cannan 1895] и был далее развит в 20-х годах XX века [Bowley 1924; Whelpton 1936]. Он многократно описан в литературе [напр. Willekens 1990; Архангельский, Елизаров 2016] и широко распространен в международной практике. Тем не менее порядок учета компонент и расчет параметров могут варьироваться и тем самым влиять на результаты. Поэтому уделим внимание некоторым деталям алгоритма, применяемого в настоящее время в Германии.

\section{1 Особенности алгоритма когортно-компонентной модели ФСУ Германии}

Население на конец базисного года распределяется по полу и возрасту от 0 до 110 лет. Для того чтобы определить, сколько женщин/мужчин (далее пол будет обозначен $g$ ) одинакового возраста доживет от конца одного до конца следующего года, используются данные об их численности на конец исходного года и соответствующие коэффициенты смертности ${ }^{4}$ Коэффициенты дожития из таблиц смертности не применяются, так как они

\footnotetext{
${ }^{4}$ О соотношении частоты и вероятности события см. [Андреев 1972]. 
показывают, с какой вероятностью лицо, дожившие до точного возраста $x$, доживет до точного возраста $(x+1)$. Для перспективного расчета необходимо, однако, знать не только вероятность дожития до возраста $(x+1)$, но и до конца календарного года, в котором этот возраст был достигнут. Поэтому алгоритм расчетов предусматривает следующее преобразование вероятности умереть $\left(q_{x, j}^{(g)}\right)$ в условную вероятность дожить от конца года $j$ до конца года $(j+1)$ :

$p_{x, j}^{(g)}=p$ (дожить до 31.12. $(j+1)$, если лицо дожило до 31.12.j) $=\frac{\left(1-q_{x, j}^{(g)}\right)\left(1-q_{X+1, j+1}^{(g)} / 2\right)}{\left(1-q_{x, j}^{(g) / 2}\right)}$.

Исходя из населения $P_{x-1, j-1}$, в течение года $j$ умирают $\left(1-p_{x-1, j-1}\right) P_{x-1, j-1}$ человек и рождаются $f_{x, j} P_{x, j}^{w}$ детей (верхним индексом $w$ обозначается женское население).

При учете миграции $\left(M_{x, j}^{(\mathrm{g})}\right.$ - сальдо эмигрантов и иммигрантов пола $g$ и возраста $x$ в году $j$ ) делается допущение, что эмигранты и иммигранты в среднем полгода находятся на рассматриваемой территории. Поэтому население в возрасте $x$ лет, пола $g$ на 31.12.j для всех когорт старше нулевого возраста $(x>0)$ рассчитывается по формуле:

$$
\begin{aligned}
P_{x, j}^{(g)} & \approx P_{x-1, j-1}^{(g)}+M_{x, j}^{(g)}-\left(1-p_{x-1, j-1}^{(g)}\right)\left(P_{x-1, j-1}^{(g)}+M_{x, j}^{(g)} / 2\right) \\
& =p_{x-1, j-1}^{(g)} P_{x-1, j-1}^{(g)}+\left(1+p_{x-1, j-1}^{(g)}\right) M_{x, j}^{(g)} / 2 .
\end{aligned}
$$

Таким образом, полученное на конец прогнозного года население включает: а) иммигранток $(Z)$; б) эмигранток $(A)$ детородных возрастов. В рамках модели для них допускается половина возрастной вероятности родить ребенка в течение того полугодия, когда они находились на рассматриваемой территории:

$$
\text { a) } f_{x, j}\left(1+p_{x-1, j-1}^{(w)}\right) Z_{x, j}^{(w) / 4} \text { или б) } f_{x, j}\left(1+p_{x-1, j-1}^{(w)}\right) A_{x, j}^{(w) / 4} \text {. }
$$

В целом число рождений на 31.12.j следовательно составляет:

$$
B_{j}^{(g)}=\sum_{x} f_{x, j}^{(g)}\left(P_{x, j}^{(w)}-\left(1+p_{x-1, j-1}^{(w)}\right) M_{x, j}^{(w)} / 4\right)
$$

Численность нулевой когорты с учетом младенческой смертности исчисляется по формуле:

$$
P_{0, j}^{(g)} \approx p_{0, j}^{(g)} \sum_{x} f_{x, j}^{(g)}\left(P_{x, j}^{(w)}-\left(1+p_{x-1, j-1}^{(w)}\right) M_{x, j}^{(w)} / 4\right)+\left(1+p_{0, j}^{(g)}\right) M_{0, j}^{(g)} / 2,
$$

где $p_{0, j}^{(g)}$ - вероятность для новорожденного пола $g$ в году $j$ дожить до 31.12.j.

Младенческая смертность распределяется неравномерно в течение первого года жизни, так как вероятность умереть в первом полугодии значительно выше, чем во втором. Если этого не учесть, то смертные случаи будут неверно распределены по календарным годам, а размер нулевой когорты будет систематически завышаться. Поэтому вводится 
корректирующий коэффициент, соответствующий доле умерших в первом полугодии в общей численности умерших в течение первого года жизни. В настоящее время он составляет для мальчиков $\alpha \approx 0,90$, а для девочек $\alpha \approx 0,89$. Вероятность дожития для нулевой когорты рассчитывается по формуле:

$$
p_{0, j}^{g}=1-\alpha q_{0, j}^{g} .
$$

\section{2 Исходная информация}

Говоря об исходной информации, мы делаем различие между непосредственно прогнозным расчетом и формированием гипотез. Источником данных для самого расчета является текущая статистика населения. Население на конец базисного года распределяется по полу и году рождения (годовым когортам). Возрастные коэффициенты рождаемости для девочек пересчитываются со среднегодовых на конец года. При этом в знаменателе коэффициентов среднегодовое женское население заменяется на население по состоянию на 31 декабря. Возрастные коэффициенты смертности получают из таблицы смертности базисного периода.

База данных для формирования гипотез гораздо шире. Сюда входят динамические ряды возрастных и суммарных коэффициентов рождаемости для гипотетических (условных) и реальных поколений на базе текущей статистики, а также распределение женских когорт по числу рождений на базе данных обследования домохозяйств ${ }^{5}$. Для гипотез по ожидаемой продолжительности жизни используются динамические ряды половозрастных коэффициентов смертности за период с конца XIX века.

Предположения по сальдо внешней миграции основываются, в первую очередь, на данных о внешней эмиграции и иммиграции начиная с 1950 г. Помимо этого привлекаются экспертные оценки и данные ООН по демографической и экономической ситуации в типичных для Германии регионах - источниках миграции, а также вся имеющаяся в распоряжении информация о факторах, которые могут повлиять на миграционные потоки в будущем. Для детальных гипотез по половозрастной структуре мигрантов рассчитываются среднегодовые распределения прибывающих и выбывающих из страны. При этом учитывается, что половозрастные распределения в период сильной миграции могут быть иными, чем в период миграционного «затишья».

Внутренняя миграция между федеральными землями рассчитывается для каждого прогнозируемого года одновременно для всех 16 федеральных земель. Предположения базируются на данных за последние три года об удельной доле выбывающих в населении каждой земли по половозрастным группам. Произведение исходной численности населения определенной когорты и соответствующей процентной доли даёт всегда отличное от нуля число выбывающих из конкретной земли в прогнозном периоде. Выбывающее из данной земли население является одновременно прибывающим в остальных 15 землях.

\footnotetext{
${ }^{5}$ Обследование домохозяйств Mikrozensus охватывает ежегодно 1\% населения; каждые 4 года в рамках этого обследования женщины в возрасте от 15 до 75 лет опрашиваются о числе рожденных ими детей [Statistisches Bundesamt 2017c; Bujard et al. 2015; Schwarz 2001].
} 
Распределение выбывающих по землям осуществляется в свою очередь в соответствии с удельными долями, наблюдавшимися за последние три года базисного периода.

\section{3. ГИПОТЕЗЫ И ДИЗАЙН ПЕРСПЕКТИВНЫХ РАСЧЕТОВ}

В основе гипотез лежит анализ долговременных трендов и актуальных тенденций основных демографических процессов: рождаемости, смертности и миграции. По каждому из этих процессов принимаются, как правило, две или три гипотезы. Каждая из них рассматривается как сценарий, реально возможный, исходя из всей имеющейся на настоящий момент информации.

Все гипотезы комбинируются между собой в варианты перспективного расчета. При этом сознательно избегается традиционная схема из высокого, среднего и низкого вариантов. Такая схема неизбежно ведет к тому, что средний вариант трактуется пользователями как наиболее вероятный. ФСУ Германии придерживается, однако, точки зрения, что одной вероятной траектории будущего развития быть не может. В развитии рождаемости и смертности всегда возможны вариации тренда. Предположения по миграции могут в лучшем случае обозначить границы, в которых будет варьироваться среднее сальдо миграции в течение длительного периода. Принцип транспарентности требует поэтому уже в дизайне перспективных расчетов учитывать присущую будущему неопределённость, с чем должны считаться и пользователи. В идеальном случае это должна быть продуманная система вариантов реально возможных траекторий будущего развития.

(Заметим в скобках: было бы, конечно, наивно утверждать, что такая трактовка официальных перспективных расчетов устраивает всех. Уже в 1972 г. известный американский демограф Натан Кейфиц метко заметил, что «демографы делают расчеты будущего населения обычно как проекцию. ... Но пользователь, как правило, не профессиональный демограф, и он ожидает предсказания того, что действительно произойдет в будущем» ${ }^{6}$ [Keyfitz 1972: 353]. Стремление принять одну единственную долгосрочную проекцию за надежный прогноз (предсказание) будущего существует, конечно, и у части пользователей в Германии [zur Nieden et al. 2016; Pötzsch 2016a]).

Помимо вариантов, перспективные расчеты ФСУ всегда включают так называемые дополнительные модели. Такие модели основаны на предположениях, представляющих интерес с аналитической точки зрения, но маловероятных как сценарий будущего развития. Это, например, предположения с нулевым и со стабильно завышенным сальдо миграции, с коэффициентом суммарной рождаемости на уровне простого воспроизводства $(2,1$ ребенка на женщину) или с замедленным ростом ожидаемой продолжительности жизни.

Последний 13-й координированный перспективный расчет включал 8 вариантов и 3 дополнительных модели [Statistisches Bundesamt 2015b; Pötzsch 2016а] (таблицы 1,2).

${ }^{6}$ Перевод автора из текста оригинала. 


\section{Таблица 1. Основные гипотезы 13-го координированного перспективного расчета} для Германии

\begin{tabular}{|c|c|c|c|}
\hline Компоненты/гипотезы & Тренд & \multicolumn{2}{|c|}{ Параметры } \\
\hline Рождаемость & & $\begin{array}{c}\text { Коэффициент суммарной } \\
\text { рождаемости, рождений на } \\
\text { женщчину }\end{array}$ & $\begin{array}{c}\text { Средний возраст матери при } \\
\text { рождении ребенка, лет }\end{array}$ \\
\hline База 2013 г. & & 1,4 & 30,7 \\
\hline Гипотеза G1 & $\begin{array}{l}\text { Почти } \\
\text { неизменный }\end{array}$ & $\begin{array}{c}1,4 \text { (в актуализированном } \\
\text { прогнозном расчете на базе } \\
2015 \text { г. гипотеза G1 } \\
\text { соответствовала КСР=1,5) }\end{array}$ & $\begin{array}{c}\text { Повышение до 31,8; } \\
\text { 2028-2060 гг. стабильный }\end{array}$ \\
\hline Гипотеза G2 & $\begin{array}{l}\text { Легкое } \\
\text { повышение }\end{array}$ & $\begin{array}{c}\text { Повышение до 1,6; } \\
\text { 2028-2060 гг. стабильный }\end{array}$ & $\begin{array}{c}\text { Повышение до 31,4; } \\
\text { 2028-2060 гг. стабильный }\end{array}$ \\
\hline Смертность & & $\begin{array}{c}\text { Ожидаемая } \\
\text { продолжительность жизни } \\
\text { при рождении, лет }\end{array}$ & $\begin{array}{c}\text { Ожидаемая } \\
\text { продолжительность жизни в } \\
\text { возрасте } 65 \text { лет, лет }\end{array}$ \\
\hline $\begin{array}{l}\text { База } \\
2010-2012 \text { гг. }\end{array}$ & & $\begin{array}{l}\text { мальчики - 77,72 } \\
\text { девочки - 82,80 }\end{array}$ & $\begin{array}{l}\text { мужчины - 17,46 } \\
\text { женщины - 20,74 }\end{array}$ \\
\hline Гипотеза L1 & $\begin{array}{l}\text { Умеренное } \\
\text { повышение } \\
\text { до } 2060\end{array}$ & $\begin{array}{l}\text { мальчики - 84,77 } \\
\text { девочки - 88,80 }\end{array}$ & $\begin{array}{l}\text { мужчины - 21,96 } \\
\text { женщины - 25,05 }\end{array}$ \\
\hline Гипотеза L2 & $\begin{array}{l}\text { Сильное } \\
\text { повышение } \\
\text { до } 2060\end{array}$ & $\begin{array}{l}\text { мальчики - 86,72 } \\
\text { девочки - 90,42 }\end{array}$ & $\begin{array}{l}\text { мужчины - 23,65 } \\
\text { женщины - 26,55 }\end{array}$ \\
\hline База 2014 г. & - & $\begin{array}{c}\text { Годовое сальдо миграчии, } \\
\text { человек }\end{array}$ & $\begin{array}{c}\text { Сальдо за период } \\
\text { с } 2014 \text { по } 2060 \text { г. } \\
\text { (среднегодовое) } \\
\text { кумулятивное): } \\
\text { - }\end{array}$ \\
\hline Гипотеза W1 & $\begin{array}{l}\text { Долгосрочный, } \\
\text { нижняя } \\
\text { граница }\end{array}$ & $\begin{array}{c}\text { Постепенное снижение до } \\
100000 \text { в } 2021 \text { г., затем } \\
\text { постоянный уровень до } \\
2060 \text { г. }\end{array}$ & $\begin{array}{l}130000 \text { чел. в год/ } \\
\text { 6,2 млн чел. }\end{array}$ \\
\hline Гипотеза W2 & $\begin{array}{l}\text { Долгосрочный, } \\
\text { верхняя } \\
\text { граница }\end{array}$ & $\begin{array}{c}\text { Постепенное снижение до } \\
200000 \text { в } 2021 \text { г., затем } \\
\text { постоянный уровень до } \\
2060 \text { г. }\end{array}$ & $\begin{array}{c}230000 \text { чел. в год/ } \\
10,6 \text { млн чел. }\end{array}$ \\
\hline
\end{tabular}

Комбинации гипотез G1-L1-W1 (1-й вариант) и G1-L1-W2 (2-й вариант) показывают, как будет развиваться население до 2060 г., если наблюдаемые до базисного периода тенденции в рождаемости и смертности будут продолжаться и в будущем, а позитивное сальдо миграции будет варьироваться с 2021 до 2060 г. в пределах от 100 до 200 тыс. человек в год. Таким образом, данные варианты образуют коридор, в пределах которого будет развиваться население Германии в случае продолжения демографических трендов ${ }^{7}$. Комбинация гипотез G2-L1-W2 (6-й вариант) иллюстрирует относительно молодую модель населения с реально возможным, но до момента проведения расчетов ещё не

\footnotetext{
${ }^{7}$ URL: https://service.destatis.de/bevoelkerungspyramide/index.html\#l=ru (дата обращения: 21.12.2017).
} 
наблюдавшимся, повышением рождаемости, умеренным ростом продолжительности жизни и относительно высоким сальдо миграции. В отличие от этого варианта, комбинация G1L2-W1 (3-й вариант) демонстрирует противоположный сценарий: с быстрым старением населения при устойчиво низкой рождаемости, ускоренном росте продолжительности жизни и относительно низком сальдо миграции. Прочие комбинации показывают, в частности, в каких границах может варьироваться численность населения, исходя из сделанных предположений.

\section{Таблица 2. Гипотезы дополнительных моделей}

\begin{tabular}{|c|c|c|}
\hline Компоненты/гипотезы & \multicolumn{2}{|c|}{ Параметры } \\
\hline Рождаемость & $\begin{array}{c}\text { Коэффициент суммарной рождаемости, } \\
\text { рождений на женщฺину }\end{array}$ & $\begin{array}{c}\text { Средний возраст матери при } \\
\text { рождении ребенка, лет }\end{array}$ \\
\hline Гипотеза G3 & $\begin{array}{c}\text { Подъем до уровня простого } \\
\text { воспроизводства, } \\
\text { с } 2015 \text { г. стабильно } 2,1\end{array}$ & $\begin{array}{l}\text { Повышение до } 31,2 ; \\
\text { с } 2015 \text { г. стабильный }\end{array}$ \\
\hline Миграция & Годовое сальдо миграции, человек & $\begin{array}{c}\text { Сальдо за период } \\
\text { с } 2014 \text { по } 2060 \text { г. } \\
\text { (среднегодовое/кумулятивное): }\end{array}$ \\
\hline Гипотеза W0 & Нулевой баланс иммиграции и эмиграции & $0 / 0$ \\
\hline Гипотеза W3 & 300000 с 2015 г. & 300000 чел. в год,/14,3 млн чел. \\
\hline
\end{tabular}

Ни в одном из этих вариантов, впрочем, не был и не мог быть предусмотрен беспрецедентный рост иммиграции в Германию в 2015 г. За один год население страны выросло почти на миллион человек. Поскольку еще не ясно, как будет развиваться миграция (в особенности из кризисных регионов восточной Азии) в дальнейшем и как она повлияет на демографические процессы, в частности на рождаемость, ФСУ Германии ограничилось в начале 2017 г. лишь актуализацией второго варианта 13-го координированного перспективного расчета (G1-L1-W2) [Statistisches Bundesamt 2017a]. Он базируется на данных о населении по состоянию на 31.12.2015 и актуализированных исходных коэффициентах рождаемости и смертности. Принятые ранее гипотезы о развитии рождаемости и смертности остались неизменными, сальдо миграции на период с 2016 до 2019 г. было повышено, а с 2020 г. соответствует прежним предположениям. Очередной 14й перспективный расчет планируется на начало 2019 г.

Подходы к поиску гипотез различаются в зависимости от специфики демографического процесса. В следующем разделе мы рассмотрим, как были обоснованы гипотезы 13-го перспективного расчета по рождаемости и как они выдерживают проверку временем.

\section{4. ГИПОТЕЗЫ О ПЕРСПЕКТИВАХ РАЗВИТИЯ РОЖДАЕМОСТИ В ГЕРМАНИИ}

\section{1 Подход и исходная информация}

Гипотезы по рождаемости формулируются, как правило, для коэффициента суммарной рождаемости условных поколений (КСР для календарных лет) и параметров возрастного 
распределения коэффициентов рождаемости, таких как, например, модальный или средний возраст матери при рождении ребенка [Архангельский, Елизаров 2016]. Третья составляющая, влияющая на число рождений в календарном году, - численность женского населения в детородных возрастах - вытекает из структуры и численности населения в базисном и прогнозном периодах.

В официальных перспективных расчетах населения Германии коэффициент суммарной рождаемости является не объектом моделирования предположений, а его следствием. В основе моделирования гипотез лежат анализ и экстраполяция возрастных трендов рождаемости, с одной стороны, и предположения о развитии среднего итогового числа детей реальных поколений, с другой. Таким образом, формальная экстраполяция возрастных трендов контролируется с учетом предположений о репродуктивном поведении реальных женских поколений и их вкладе в календарную рождаемость. Это особенно важно, поскольку динамические ряды возрастных коэффициентов отчасти подвержены колебаниям и формальная экстраполяция тренда недостаточно надежна.

Большое внимание уделяется также аналитическому обоснованию предположений. При этом исходная информация и тенденции в самой рождаемости во многом предопределяют пути поиска гипотез.

Главными источниками данных являются макропоказатели статистики рождаемости, с одной стороны, и результаты $1 \%$-го обследования домашних хозяйств, с другой. При выборе методов анализа приходится считаться с ограниченностью исходной информации. Например, данные об очередности рождений в течение жизни женщины имеются в статистике рождаемости Германии в полном объеме только с 2009 г. До этого регистрировалась только очередность рождений в текущем браке (исключение составляет статистика ГДР до 1989 г.). Так как с начала 1990-х годов доля внебрачных рождений и повторных браков последовательно росла, то использование распределения по очередности рождений сильно ограничено и не позволяет, в частности, на настоящий момент анализировать специальные таблицы по очередности рождений ${ }^{8}$ [Luy, Pötzsch 2011]. На основе репрезентативных данных обследования домохозяйств возможен, однако, анализ распределения реальных поколений по числу рожденных детей. Эта информация является важным дополнением текущей статистки рождаемости.

\section{2 Тенденции, лежащие в основе предположений о будущем развитии рождаемости в Германии}

Уровень рождаемости в Германии чрезвычайно низок даже на фоне относительно низкой рождаемости в развитых странах мира, редко достигающей уровня простого воспроизводства (т.е. КСР в размере 2,1 ребенка на женщину). Помимо этого коэффициент суммарной рождаемости находится уже более 40 лет в пределах от 1,3 до 1,5 рождения на

\footnotetext{
8 Модель, позволяющая оценить вероятность перехода от бездетности к первому ребенку, от первого ко второму и т.д. (Parity Progression Ratio, см. [Захаров 2017]). Поскольку полные данные о распределении по очередности рождения имеются в немецкой статистике лишь с 2009 г., то охват репродуктивного цикла (3035 лет) будет возможен самое раннее к 2039 г.
} 
женщину. В 1994 г. он достиг своего исторического минимума - 1,2 рождения на женщину, затем несколько повысился и с 1997 по 2011 г. колеблется около 1,4 рождения на женщину.

С 2012 г. в рождаемости появилась новая позитивная динамика. В преддверии предстоящего очередного 14-го перспективного расчета необходимо проанализировать, каковы ее причины и потенциал для будущего развития. В начале ознакомимся с устойчивыми тенденциями, на основании которых были приняты гипотезы о рождаемости на базе 2013 г.

\section{1. Стабильность коэффициента суммарной рождаемости условных поколений при последовательном изменении календаря рождений}

С начала 1980-х годов кумулятивная рождаемость в возрасте до 29 лет в Германии последовательно снижалась (рисунок 1). Одновременно росла частота рождений в старших детородных возрастах. Этот рост, в среднем, компенсировал снижение рождаемости в возрасте до 29 лет, что обеспечивало относительную стабильность КСР условных поколений. С 2006 г. вклад рождаемости в возрастах от 30 до 49 лет в КСР превышает вклад молодых возрастов.

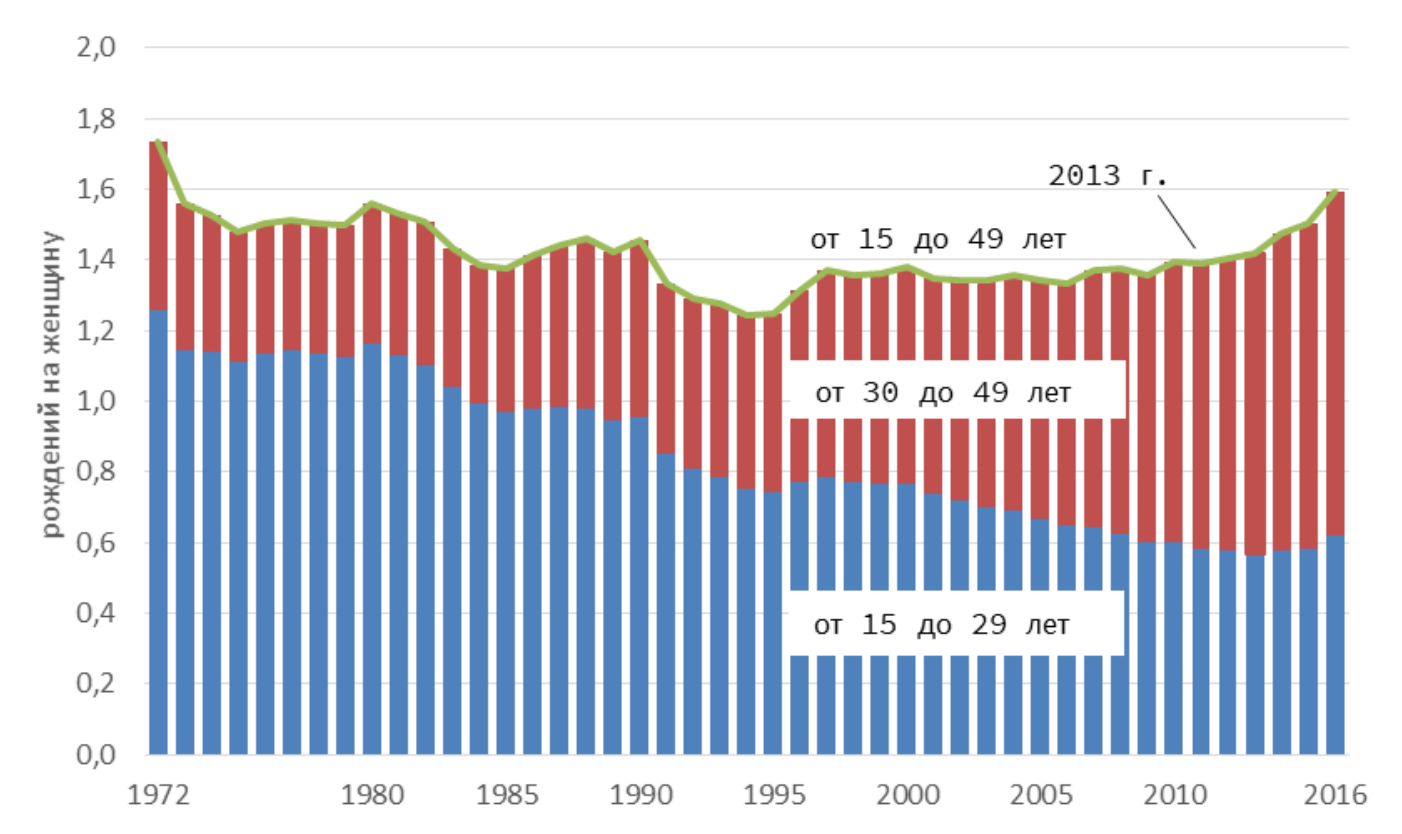

Рисунок 1. Коэффициент суммарной рождаемости и сгруппированные коэффициенты рождаемости для женщин в возрасте до и от 30 лет. Условные поколения, Германия, 1972-2016

Источник: Расчеты автора по данным ФСУ Германии.

С 2012 г. наблюдается ежегодный прирост КСР. Он был обусловлен стабилизацией рождаемости в возрасте до 29 лет, с одной стороны, и некоторым усилением роста рождаемости в старших возрастах, с другой. Эта новая тенденция, которая еще не присутствовала при разработке предположений последнего перспективного расчета на базе 2013 г., будет прослежена в репродуктивном поведении реальных поколений в разделе 4.4. 


\section{2. Рост среднего возраста матери при рождении первого ребенка}

За последние 40 лет в Германии повысился не только средний возраст при рождении ребенка для всех матерей, но прежде всего возраст матери при рождении первого ребенка. В западногерманских землях он вырос с 1970 по 2015 г. с 24 до почти 30 лет. В восточной части Германии, где календарь рождений вплоть до момента объединения Германии в 1990 г. был году очень «молодым», матери при рождении первого ребенка только за 16 лет (1989 - 2015 гг.) «постарели» в среднем на 6 лет: с 23 до почти 29 лет. В целом по Германии средний возраст женщин при рождении первого ребенка составил в 2015 г. 29,7 года. Соответственно, число и доля «молодых» матерей постоянно уменьшается, а фактический детородный период - с момента рождения первого ребенка до завершения репродуктивной фазы - сужается.

\section{3. Снижение итоговой рождаемости реальных поколений по мере повышения среднего возраста матери}

В отличие от КСР условных поколений, среднее итоговое число детей женщин реальных поколений, родившихся после 1940 г., почти последовательно снижалось вслед за снижением рождаемости в молодых возрастах (рисунок 2). Компенсация ранее не реализованных рождений в старших детородных возрастах в реальных поколениях была далеко не полной. В этом значительное отличие Германии от таких европейских стран с высоким возрастом материнства, как например, Франция или Швеция. Если в этих странах не состоявшиеся в молодых возрастах рождения были лишь «отложены» на более поздний возраст [Frejka, Sobotka 2008], то в Германии значительная часть рождений, не реализованных в молодых возрастах, так и не состоялась до завершения детородного периода.

Снижение итогового числа рождений достигнет своего минимума в когортах 1968 1969 годов рождения. Затем ожидается стабилизация и даже легкий подъем КСР реальных поколений. В основе этих изменений лежат стабилизация уровня рождаемости в возрасте до 29 лет, с одной стороны, и одновременное продолжение роста рождаемости в старших возрастах, с другой. Эта благоприятная ситуация заканчивается, однако, с возобновлением спада рождаемости в молодых возрастах в когортах начиная с 1975-го года рождения. Пока мы не знаем, какова будет рождаемость этих поколений в ближайшие годы. Но если даже она будет повышаться в том же темпе, как за последние десять лет, то в результате будет лишь компенсировано снижение рождаемости в возрасте до 29 лет. Более того, в возрастах от 36 до 40 лет компенсация должна быть такой же сильной, как и в возрастах от 30 до 35 лет, являющихся в настоящее время главными детородными возрастами [Sobotka et al. 2011; Pötzsch 2013, 2016b]. Уже это условие показывает, что такое предположение является довольно оптимистичным сценарием. Для последовательного же роста итогового числа детей необходима была бы рождаемость в возрастах от 30 до 49 лет, превышающая необходимую компенсацию «отложенных» рождений. Такой сценарий представляется маловероятным, как показывает последующий анализ тенденций в распределении женщин по числу рождений. 


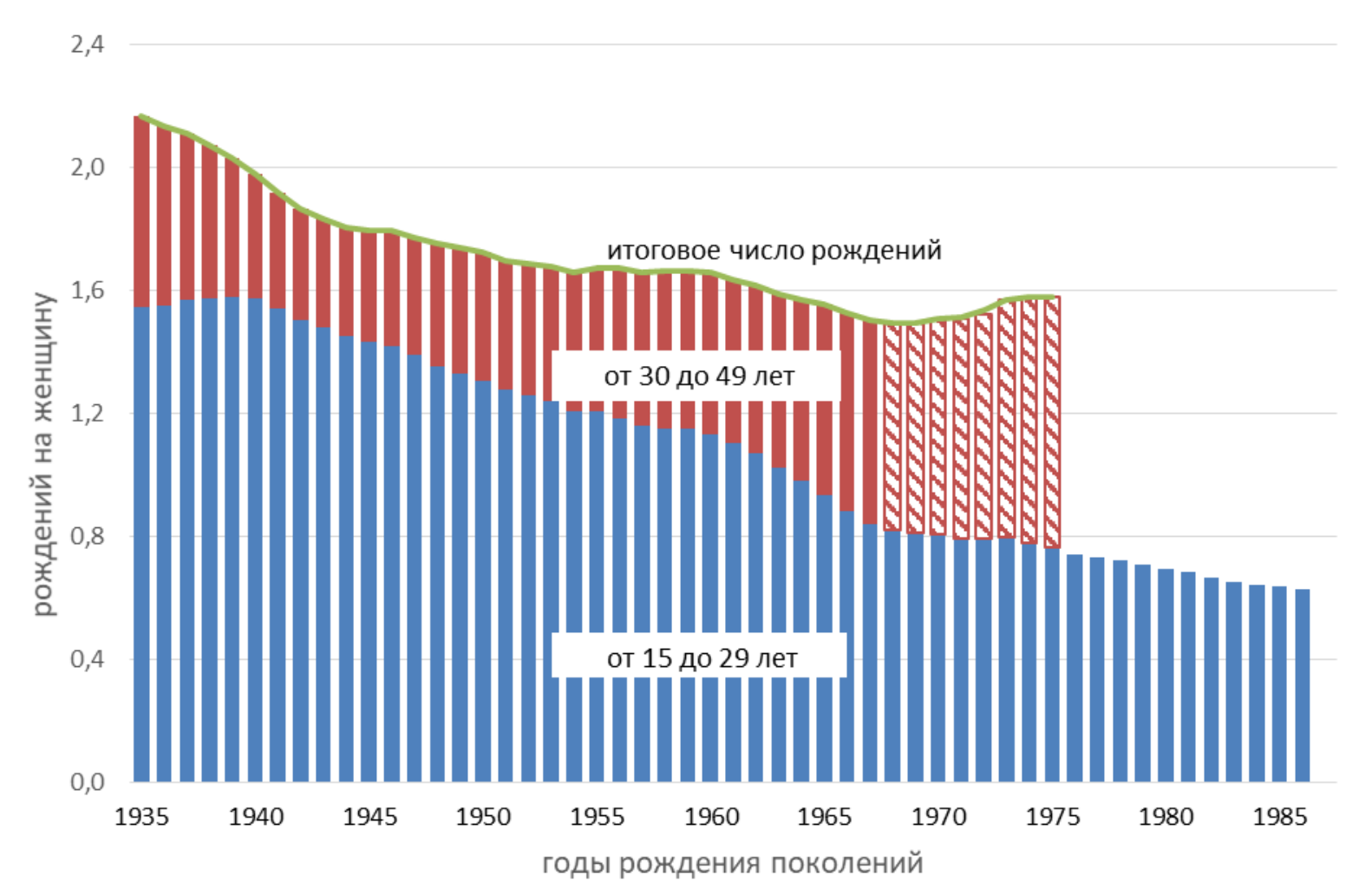

Рисунок 2. Итоговое число рождений на женщину и кумулятивная рождаемость в возрасте до и от 30 лет. Реальные поколения, Германия, 1935-1986 годы рождения

Источник: Расчеты автора по данным ФСУ Германии.

Примечание: Для женщин 1968 - 1975 годов рождения, находившихся в 2016 г. ещеё в детородном возрасте, предварительная оценка.

\section{4. Рост уровня бездетности реальных поколений}

Одной из самых значимых тенденций динамики рождаемости в Германии является последовательный рост окончательной бездетности. За тридцатилетний период между когортами 1937 и 1967 годов рождения доля никогда не рожавших женщин в общей численности женщин реального поколения удвоилась с 11 до 21\% (рисунок 3; пунктирные линии показывают когорты в позднем детородном возрасте, которые уже достигли рубежа окончательной бездетности: в Германии на настоящий момент это 42 года).

Германия - не единственная европейская страна со столь высоким уровнем бездетности. По данным Т. Соботки [Sobotka 2017: 37], в Швейцарии, Финляндии, Италии и Ирландии также приблизительно каждая пятая женщина, родившаяся в конце 1960-х годов, бездетна. 


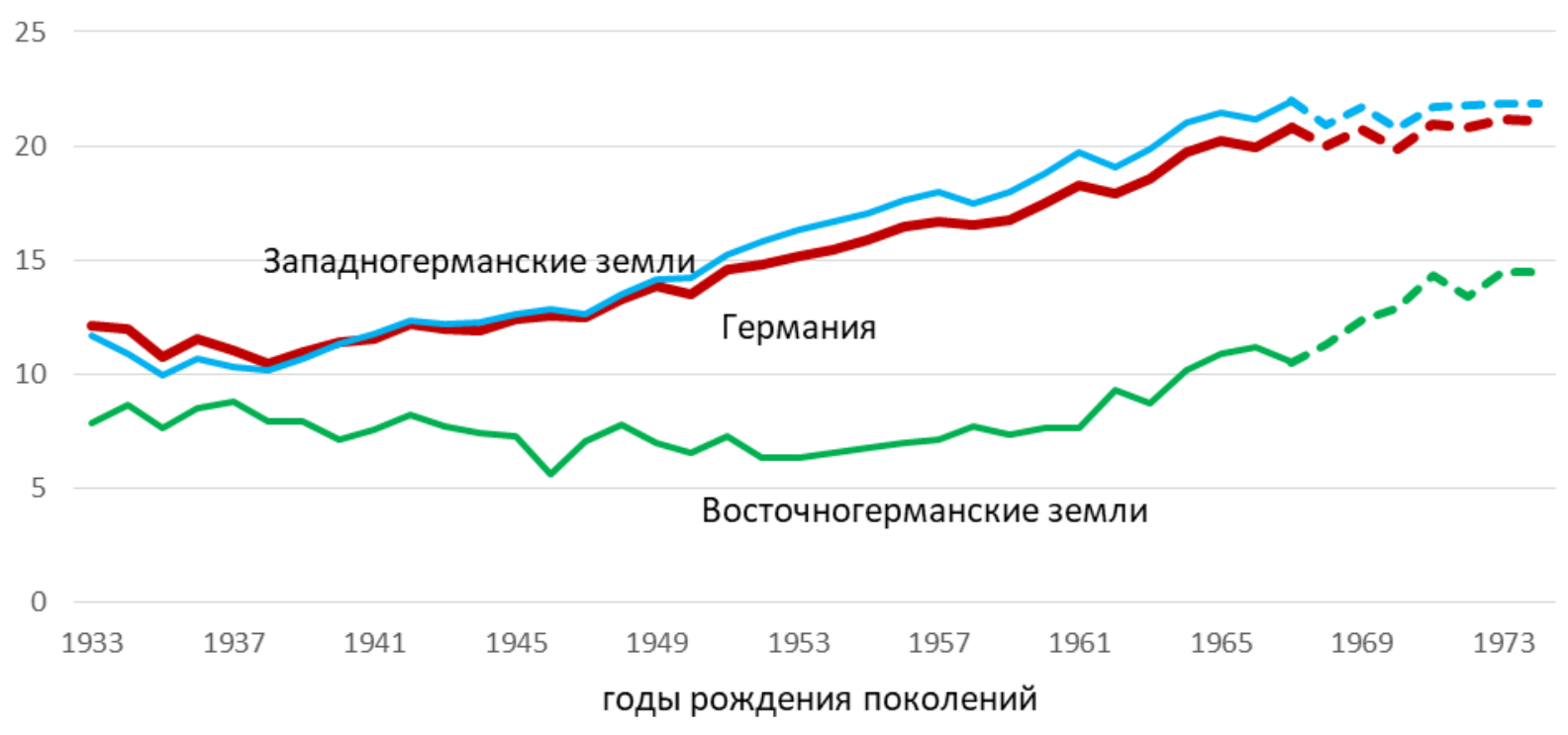

Рисунок 3. Доля бездетных в общей численности женщин реальных поколений, Германия, 1933-1974 годы рождения, \%

Источник: Результаты выборочного обследования домохозяйств: Mikrozensus 2008, 2012 и 201622. [Statistisches Bundesamt 2017c].

Примечание: Для поколений, достигших кмоменту обследования в 2016 г. возраста 42 года.

Тенденция к стабилизации итоговой бездетности впервые проявилась по данным обследования домохозяйств Mikrozensus c 2013 г. В поколениях конца 1960-х - начала 1970-х годов рождения доля бездетных женщин стабилизировалась на относительно высоком уровне 20-21\% [Statistisches Bundesamt 2017c]. Стабилизация уровня бездетности по Германии в целом была обусловлена изменениями в репродуктивном поведении западногерманских женщин, чей уровень бездетности до сих пор на одну треть выше, чем у женщин в восточной части Германии. Одновременно, наблюдается дальнейшее повышение бездетности восточногерманских женщин и женщин-мигранток.

Среди женщин с высшим образованием бездетность хотя и снизилась с $28 \%$ (когорты конца 1960-х годов) до 25\% (когорты начала 1970-х годов), но ее уровень все еще очень высок. Поэтому дальнейшее распространение высшего образования может при неизменных условиях для академической карьеры способствовать росту общего уровня бездетности. Таким образом, даже с учетом текущих позитивных тенденций снижение итоговой бездетности в Германии ниже $20 \%$ в среднесрочной перспективе маловероятно.

\section{5. Среднее число детей у матерей в реальных поколениях может утерять свою стабильность}

Несмотря на относительно высокий уровень бездетности, 8 из 10 женщин родили за свою жизнь минимум одного ребенка. При этом среднее число детей в поколениях матерей 1940х годов рождения снизилось, по сравнению с поколениями 1930-х годов, с 2,3 до 2,0 ребенка на одну мать, а доля матерей с четырьмя и более детьми упала в два раза (с 12 до 6\%). Впоследствии распределение матерей по числу детей стабилизировалось и претерпевало лишь незначительные колебания вплоть до поколений начала 1970-х годов рождения. При этом примерно каждая третья мать имеет одного ребенка (31\%), каждая вторая - двух детей 
(48\%) и каждая пятая - трех и более детей (21\%) [Statistisches Bundesamt 2017c].

В будущем среднее число детей на мать может, однако, утерять свою стабильность. Поскольку все больше женщин откладывают рождение первого ребенка, уменьшается число молодых матерей, а тем самым и потенциал для поддержания стабильной доли матерей с тремя и более детьми в будущем. Для современной модели репродуктивного поведения в Германии свойственна закономерность: чем ниже средний возраст матери при рождении первого ребенка, тем больше среднее итоговое число детей на одну мать. Результаты обследования домохозяйств показали, что в поколениях, родившихся с середины 1960-х до середины 1970-х годов, матерям с одним ребенком при его рождении было в среднем 30 лет, с двумя детьми при рождении первенца - 27 лет, с тремя детьми - 25 лет, а с четырьмя и более детьми - всего 23 года [Pötzsch 2016b: 108].

\section{6. Устойчивые многолетние интервалы между рождениями}

Чтобы среднее итоговое число детей на мать, несмотря на повышение среднего возраста матери при рождении первого ребенка, не снизилось, должны сократиться интервалы между рождениями. Опыт Франции и Швеции показывает, что при этом условии высокий средний возраст рождения первого ребенка не обязательно ведет к низкой итоговой рождаемости [Frejka, Sobotka 2008]. Однако в Германии откладывание момента рождения первого ребенка, рост бездетности и снижение доли матерей с тремя и более детьми протекали параллельно в женских поколениях, начиная в 1947 года рождения.

Как было сказано выше, регистрация очередности новорожденных с учетом всех рождений (брачных и внебрачных) в жизни матери ведется в Германии лишь с 2009 г. Это же относится и к интергенетическим интервалам. Начиная с 2009 г., в статистике рождаемости учитывается период времени, прошедший после рождения предыдущего ребенка у матери, независимо от того, был ли этот ребенок рожден в (том же) браке.

Наблюдаемые за этот период интервалы относительно велики и очень стабильны. Интервал, соответствующий медиане распределения, для вторых детей составляет 3,3 года. Это означает, что в $50 \%$ всех случаев второй ребенок появляется на свет по прошествии более 3 лет и 4 месяцев после рождения первенца. Половина третьих рождений происходит в течение 3 лет и 11 месяцев после рождения второго ребенка, а вторая половина - с еще большим перерывом9 ${ }^{9}$ В целом между рождением первого и третьего ребенка проходит в среднем не менее 7 лет. Эти данные текущей статистики рождаемости подтверждаются результатами обследования домохозяйств [Pötzsch 2016b; Statistisches Bundesamt 2017b].

\section{3 Гипотезы по развитию рождаемости в Германии на базе данных до 2013 2.}

На основе описанных тенденций были приняты следующие два предположения о развитии рождаемости в будущем: сохранение долговременных тенденций (G1) и легкое повышение рождаемости $(\mathrm{G} 2)$.

\footnotetext{
${ }^{9}$ URL: https://www.destatis.de/EN/FactsFigures/SocietyState/Population/Births/Tables/LiveBirthInterval.html (дата обращения: 01.12.2017).
} 
Гипотеза G1 предполагает, что в разрезе условных поколений снижение рождаемости в молодых возрастах будет и далее компенсироваться ростом рождаемости в возрастах от 30 до 49 лет (рисунок 4). Это обусловливает стабильность КСР на уровне 1,4 ребенка на женщину. Итоговая рождаемость для когорт с 1973 до 1984 года рождения сначала стабилизируется на уровне около 1,6, затем итоговый КСР реальных поколений постепенно снизится до 1,4 ребенка на женщину. В основе лежит предположение, что дальнейший «перенос» момента рождения первого ребенка на более поздний детородный возраст постепенно приведет к смещению в распределении женских поколений по числу детей. Итоговая бездетность будет расти до конца 2020-х годов ввиду более низкой вероятности первой беременности в возрастах старше 35 лет [te Velde et al. 2012]. Если интервалы между рождениями и далее будут оставаться стабильными, то «старение» модели рождаемости приведет постепенно также к снижению доли многодетных матерей. Даже сравнительно небольшое повышение доли бездетных женщин до 25 \%, что предполагает резкое замедление многолетнего тренда, и снижение среднего числа детей на мать лишь с 2,0 до 1,9 приведет к снижению КРС в ходе прогнозного периода до 1,4 ребенка на женщину (1,9 ребенка на мать * 0,75 (доля матерей в общей численности женской когорты)).

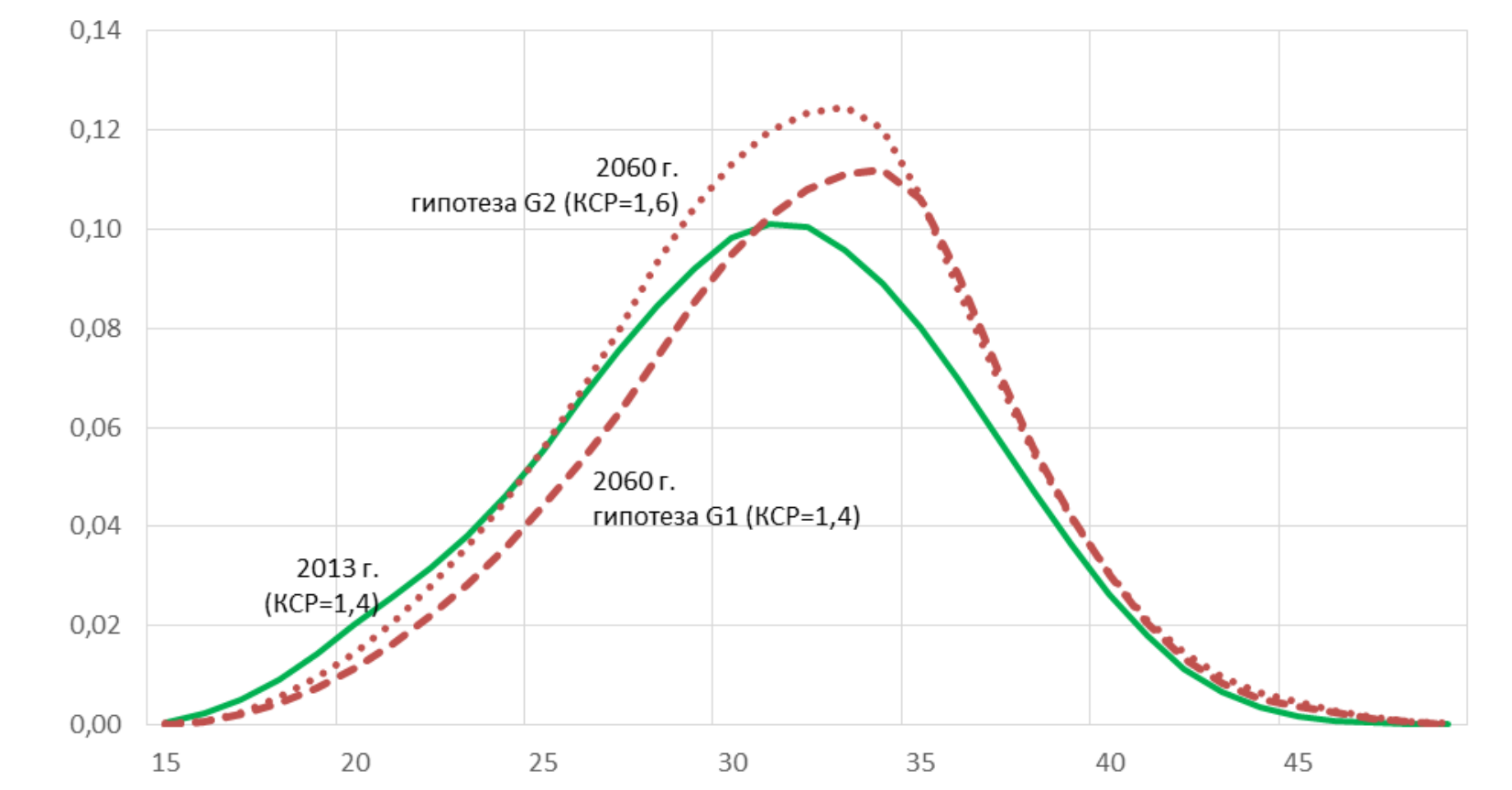

\section{Рисунок 4. Возрастные коэффициенты рождаемости условных поколений, Германия, число рождений на одну женщину}

Источник: ФСУ Германии [Statistisches Bundesamt 2015a].

Примечание: 2013 г. - данные статистики рождаемости; 2060 г. - гипотезы 13-го координированного перспективного расчета населения Германии.

Гипотеза G2 теоретически учитывает возможные изменения в репродуктивном поведении, которые могут привести к повышению КСР условных поколений до 1,6 и к стабильной итоговой рождаемости реальных поколений на уровне 1,6 ребенка на женщину. Такое развитие предполагает, однако, стабилизацию рождаемости в молодых детородных возрастах при одновременном ее повышении в возрастах от 30 лет (рисунок 4). Итоговый КСР будет в этом случае развиваться сначала так же, как в гипотезе G1, в поздних же 
когортах 1980-х годов он поднимется чуть выше 1,6 и стабилизируется на этом уровне. Предпосылками для реализации этой гипотезы является снижение и стабилизация итоговой бездетности на уровне $20 \%$ (т.е. изменение долговременного тренда) и среднее число детей на мать не менее 2,0.

\section{4. Гипотезы 13-го перспективного расчета в свете текущего роста рождаемости}

Уже наблюдавшееся в 2012 и 2013 г. легкое повышение рождаемости усилилось в 2014 2016 гг. (таблица 3). В итоге КСР рос сильнее, чем предполагалось даже по более высокой гипотезе G2 (рисунок 5), и впервые за последние 40 лет достиг 1,59 рождения на женщину. Что обусловило такой резкий подъем рождаемости и какие последствия он имеет для предположений о будущем ее развитии?

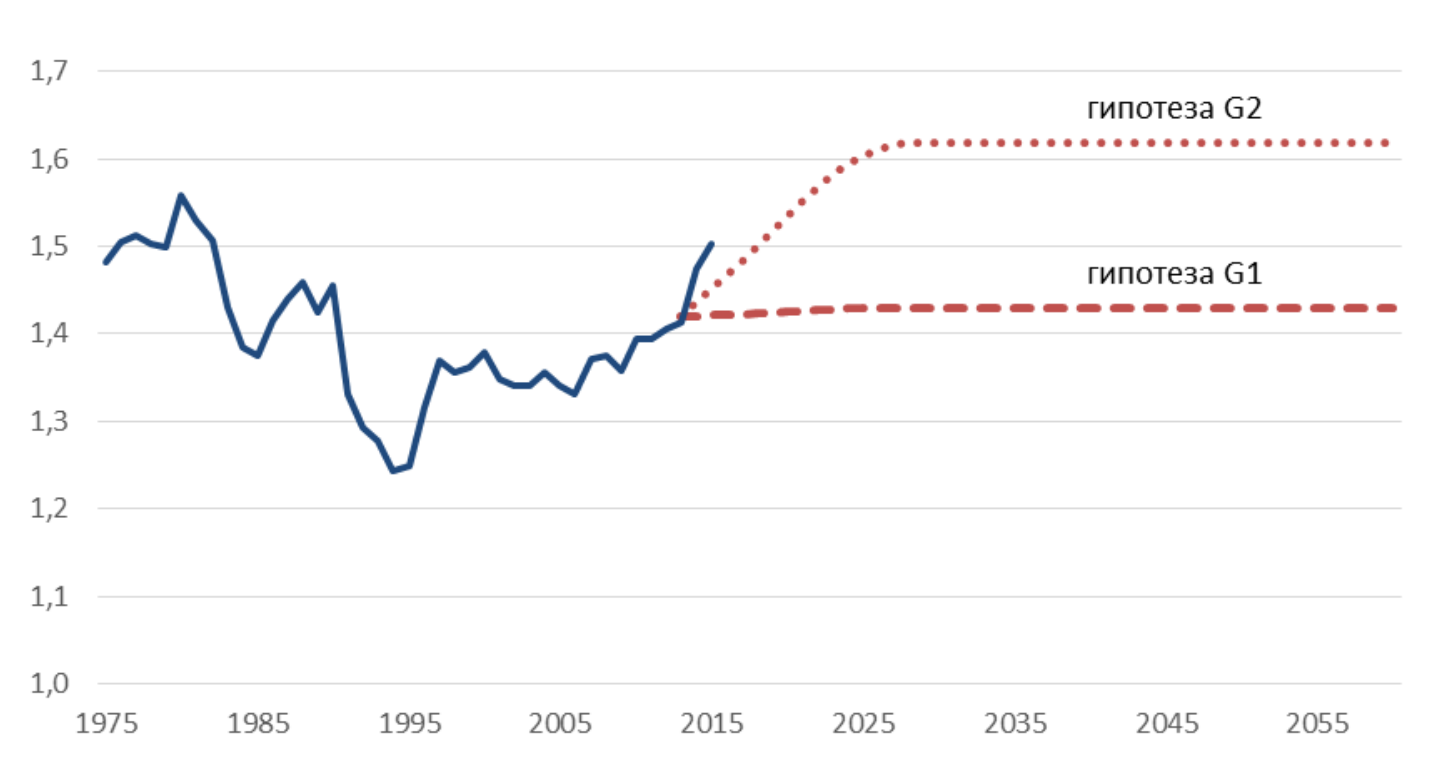

\section{Рисунок 5. Коэффициент суммарной рождаемости условных поколений, Германия, число рождений на одну женщину}

Источник: ФСУ Германии [Statistisches Bundesamt 2015a].

Примечание: 1975-2015 г2. - данные статистики рождаемости; с 2014 г. - гипотезы 13-го координированного перспективного расчета населения Германии на базе 2013 г.

Одним из лежащих на поверхности факторов роста рождаемости является, безусловно, резко усилившаяся иммиграция в Германию. К притоку иммигрантов из Румынии и Болгарии, которые с 1 января 2014 г. могли без ограничений работать на территории Европейского Союза, присоединились беженцы из Сирии, Афганистана, Ирака и некоторых африканских стран. Если в 2014 г. КСР вырос как для немецких женщин, так и для иностранок, то в 2015 и 2016 гг. подъем КСР в целом по Германии был обусловлен в первую очередь повышением рождаемости иностранок до 1,96 и 2,23 рождения на женщину соответственно (таблица 3 ). 
Таблица 3. Коэффициент суммарной рождаемости в зависимости от гражданства женщин, 2011 - 2015 гг., число рождений на одну женщину

\begin{tabular}{c|ccc|c|c|c}
\hline & \multicolumn{2}{|c|}{ Коэффициент суммарной рождаемости } & \multicolumn{3}{c}{ Изменение за год } \\
\cline { 2 - 7 } & все женщины & немки & иностранки & все женщины & немки & иностранки \\
\hline 2011 & 1,39 & 1,34 & 1,82 & - & - & - \\
2012 & 1,41 & 1,36 & 1,79 & 0,01 & 0,02 & $-0,03$ \\
2013 & 1,42 & 1,37 & 1,80 & 0,01 & 0,01 & 0,01 \\
2014 & 1,48 & 1,42 & 1,86 & 0,06 & 0,05 & 0,06 \\
2015 & 1,50 & 1,43 & 1,96 & 0,03 & 0,01 & 0,09 \\
2016 & 1,59 & 1,46 & 2,23 & 0,09 & 0,04 & 0,32 \\
\hline
\end{tabular}

Источник: Данные ФСУ Германии.

Одновременно выросло число женщин в детородных возрастах с наибольшей частотой рождений (25-39 лет). Несмотря на сокращение общего числа потенциальных матерей (в возрасте от 15 до 49 лет) за период с 2011 по 2016 г. с 17,9 млн до 17,2 млн (почти на 690 тыс., что составляет -4\%), число женщин в возрасте от 25 до 39 лет, напротив, увеличилось на 506 тыс. (+7\%). Это связано как с влиянием демографического эха, так как средних детородных возрастов достигли дочери поколения бэби-бума, так и с повышением сальдо миграции.

Общий прирост новорожденных за 2011-2016 гг. составил более 129 тыс. или 19\% (таблица 4). Прирост рождений в основной группе (женщин-немок) на 10\% был обусловлен в основном повышением возрастных коэффициентов рождаемости, т.е. ростом ее интенсивности. У иностранок прирост числа новорожденных составил $64 \%$ и стал возможен, прежде всего, в результате изменений в численности и возрастной структуре потенциальных матерей; повышение интенсивности рождаемости произошло лишь в 2015 и 2016 гг. и играло в целом менее значительную роль.

Таблица 4. Компоненты изменения числа рождений в Германии, 2011-2016

\begin{tabular}{|c|c|c|c|c|c|c|}
\hline \multirow[b]{2}{*}{ Гражданство } & \multicolumn{2}{|c|}{$\begin{array}{c}\text { Число рождений } \\
\text { у матерей в возрасте } \\
\text { от } 15 \text { до } 49 \text { лет }\end{array}$} & \multicolumn{2}{|c|}{$\begin{array}{c}\text { Изменение } \\
\text { с } 2011 \text { по } 2016 \text { г. }\end{array}$} & \multicolumn{2}{|c|}{ В том числе за счет изменений ${ }^{*}$ : } \\
\hline & 2011 & 2016 & $\begin{array}{c}\text { абсолютное } \\
\text { число } \\
\text { рождений }\end{array}$ & $\begin{array}{c}\text { В \% } \\
\text { К } 2011 \text { г. }\end{array}$ & $\begin{array}{c}\text { в числе и } \\
\text { возрастной } \\
\text { структуре } \\
\text { женщин } \\
\end{array}$ & $\begin{array}{c}\text { в возрастных } \\
\text { коэффициентах } \\
\text { рождаемости }\end{array}$ \\
\hline Все женщины & 66252 & 791695 & +129169 & +19 & +32338 & +96831 \\
\hline Немки & 55020 & 607263 & +57060 & +10 & +5334 & +51726 \\
\hline Иностранки & 11232 & 184432 & +72109 & +64 & +45484 & +26625 \\
\hline
\end{tabular}

Источник: Расчеты автора по данным ФСУ Германии.

Примечание: * - Индексное разложение прироста рождений за период на основе возрастного распределения.

Вклад немок в общее число рождений снизился с 83\% в 2011 г. до 77\% в 2016 г. Снижение доли рождений у немецких женщин связано с тем, что прирост новорожденных за этот период у них был значительно меньше, чем у женщин-иностранок. Тем не менее, преобладающая масса рождений приходится на женщин с немецким гражданством. Поэтому тенденции в интенсивности их деторождения являются определяющими для будущего развития рождаемости в Германии. 
Сравнение их возрастных коэффициентов рождаемости за 2011 и 2016 гг. показывает, что к повышению КСР с 1,34 до 1,46 привел, главным образом, рост частоты рождений в возрастах от 29 до 40 лет. Этот рост был обусловлен, с одной стороны, эффектами в календарной рождаемости. К ним относится, в частности, сближение средних детородных возрастов по очередности рождений, наблюдавшееся в 2012 - 2016 гг. у немок в отношении вторых и третьих рождений ${ }^{10}$.

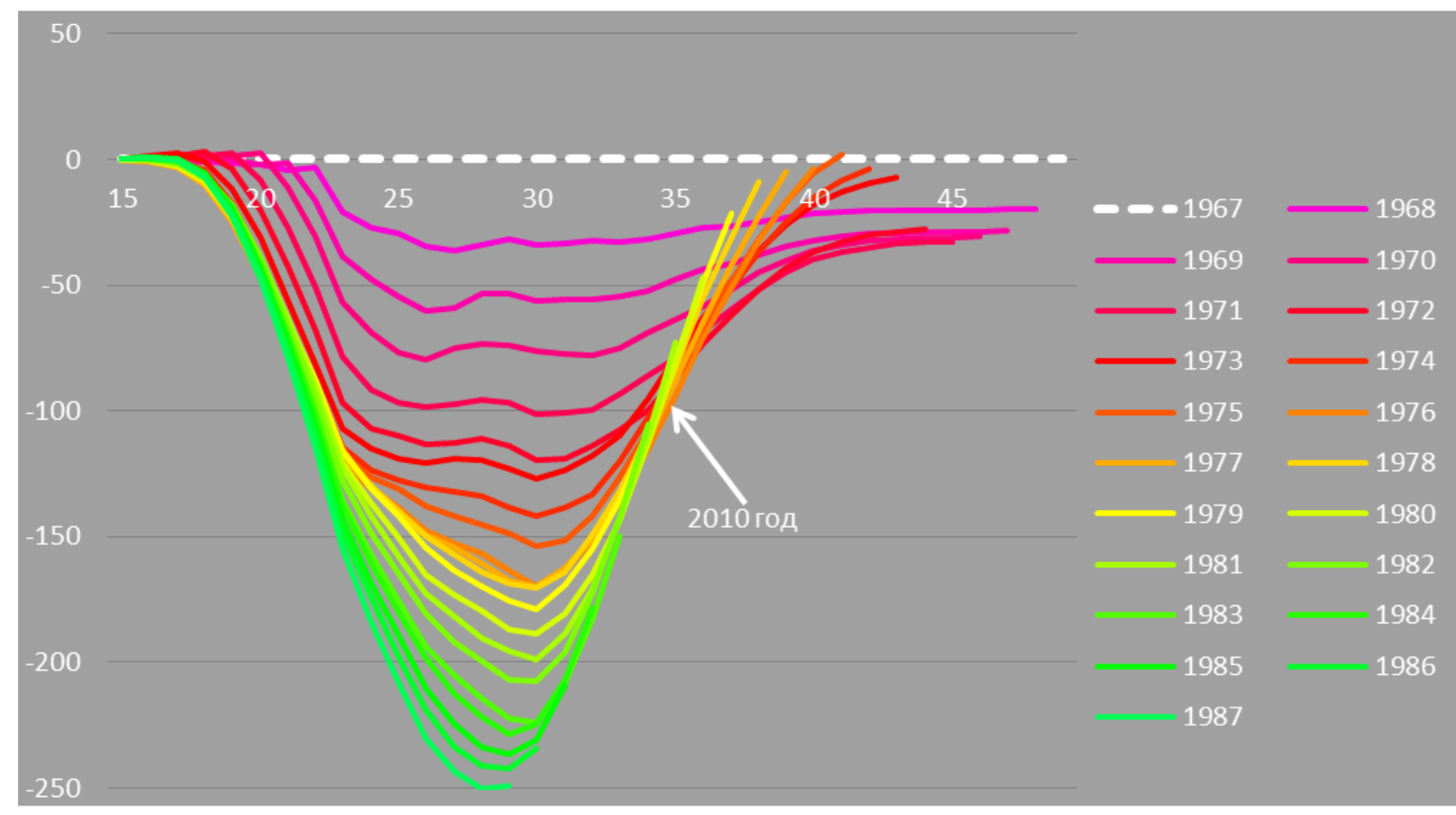

Рисунок 6. Отклонение кумулятивных коэффициентов рождаемости реальных поколений немецких женщин от кумулятивной рождаемости когорты 1967 года рождения

Источник: Расчеты автора по данным ФСУ Германии.

С другой стороны, источником этих изменений являются особенности репродуктивного поведения соответствующих реальных поколений. В 2012-2016 гг. в возрасте от 29 до 40 лет находились женщины 1972-1987 годов рождения. Для женщин этих когорт было характерно последовательное снижение кумулятивной рождаемости в возрасте до 30 лет. Для женщин этих когорт было характерно последовательное снижение рождаемости в молодых возрастах. В возрасте от 30 лет они реализовывали ранее «отложенные» рождения. Причем по данным за 2016 г. уже очевидно, что у женщин 19721985 годов рождения этот процесс протекал более интенсивно, чем в реальных поколениях конца 1960-х годов. Рисунок 6 иллюстрирует эти процессы «откладывания» и «наверстывания» рождений в реальных поколениях немецких женщин. Цветные линии

\footnotetext{
10 Этот календарный показатель рассчитывается как разность средних детородных возрастов при рождении соответственно первого, второго, третьего и т.д. ребенка. Он отличается от интергенетического интервала, описанного в разделе 4.2, который опирается на индивидуальные данные матерей и представляет собой среднюю из временных промежутков между датами рождения соответственно второго и первого, третьего и второго, четвертого и третьего и т.д. детей матери (в Германии эти данные поступают в текущую статистику рождаемости из органов ЗАГС).
} 
показывают отклонения между кумулятивными коэффициентами рождаемости когорт 1968 - 1987 годов рождения от последней когорты с завершенным детородным циклом (1967 года рождения). Ее кумулятивную рождаемость в возрастах от 15 до 49 лет символизирует белая линия, лежащая на оси $X$. Среднее итоговое число детей для немецких женщин этой когорты составляло 1,48.

Из рисунка 6 следует, что каждая последующая когорта имела до своего 30-летия, в среднем, меньше детей, чем предыдущая. Однако благодаря усилившейся «компенсации» деторождения в старших возрастах, итоговое число детей у женщин 1970-х годов рождения будет выше, чем в когортах конца 1960-х годов. По величине оно, вероятно, достигнет 1,5 ребенка на женщину. Иными словами, усиление интенсивности рождаемости поколений в возрасте после 30 лет будет достаточным лишь для компенсации ее спада в молодых возрастах и предотвращения дальнейшего снижения итоговой рождаемости.

При соотнесении изменений в кумулятивной рождаемости реальных поколений на рисунке 6 с календарным временем становится очевидным, что «компенсация» рождений в старших возрастах усилилась приблизительно с 2010 г. В этот период ситуацию женских когорт 1972 - 1987 годов рождения в Германии можно охарактеризовать следующим образом:

- они в основном завершили свое образование, получили профессию и большинство из них имеет работу;

- в возрасте до 30 лет они родили в среднем еще меньше детей, чем предшествующие поколения конца 1960-х годов рождения с исторически низкой итоговой рождаемостью;

- дискуссия о старении населения, росте бездетности и необходимости улучшения ситуации семей с детьми достигла в это время своего разгара не только в средствах массовой информации и политических дебатах, но и в широких кругах общества;

- одновременно потеряло свою привлекательность характерное для поколений 1960-х годов достаточно сдержанное отношение к материнству, препятствующему в их восприятии эмансипации и профессиональному росту женщины;

- приняты и вступили в силу долгожданные меры семейной политики, такие как пособие для родителей по уходу за ребенком в течение первого года жизни, размер которого зависит от последней заработной платы, и законодательное право на место в яслях для детей до трех лет;

- Германия вышла из финансового кризиса 2008 г. без ощутимых потерь; экономическая стабильность и низкая безработица внушают уверенность в завтрашнем дне.

Таким образом, именно для когорт 1970-х и первой половины 1980-х годов рождения ситуация оказалась исключительно благоприятной для реализации «отложенных» рождений, и они ею воспользовались. Это привело к росту возрастных коэффициентов рождаемости в 2012 - 2016 гг., к частичной компрессии рождений различной очередности и вероятно будет влиять еще некоторое время на календарную рождаемость при условии сохранения экономической и социальной стабильности.

Несмотря на эти позитивные сдвиги, итоговое число детей в когортах немецких женщин вряд ли будет в ближайшее десятилетие устойчиво превышать уровень 1,5 ребенка 
на женщину. Ощутимый рост итоговой рождаемости в целом по Германии без участия женщин-иностранок в настоящий момент маловероятен. Как видно из рисунка 7 (зеленые пунктирные линии иллюстрируют кумулятивные коэффициенты для всех женщин в сравнении с уровнем рождаемости немок), повышение ожидаемого итогового числа детей реальных поколений первой половины 1970-х годов рождения обусловлено двумя процессами: стабилизацией кумулятивной рождаемости в возрасте до 30 лет, с одной стороны, и повышением рождаемости в возрасте после 30, с другой. Первый из этих процессов связан с усилением влияния женщин-иностранок на рождаемость в молодых возрастах вследствие роста их удельного веса в соответствующих женских когортах. Если в поколениях начала 1960-х годов рождения доля иностранок составляет 9\%, то в когортах 1970-х годов она удвоилась до 18\%. При этом рождаемость у иностранок не только выше, но имеет и более молодую возрастную модель, чем у немецких женщин. Эти факторы способствовали стабилизации рождаемости в возрасте до 30 лет и обусловили наблюдаемый в настоящее время легкий подъем итогового числа детей до (ожидаемого) уровня 1,57 ребенка на женщину.

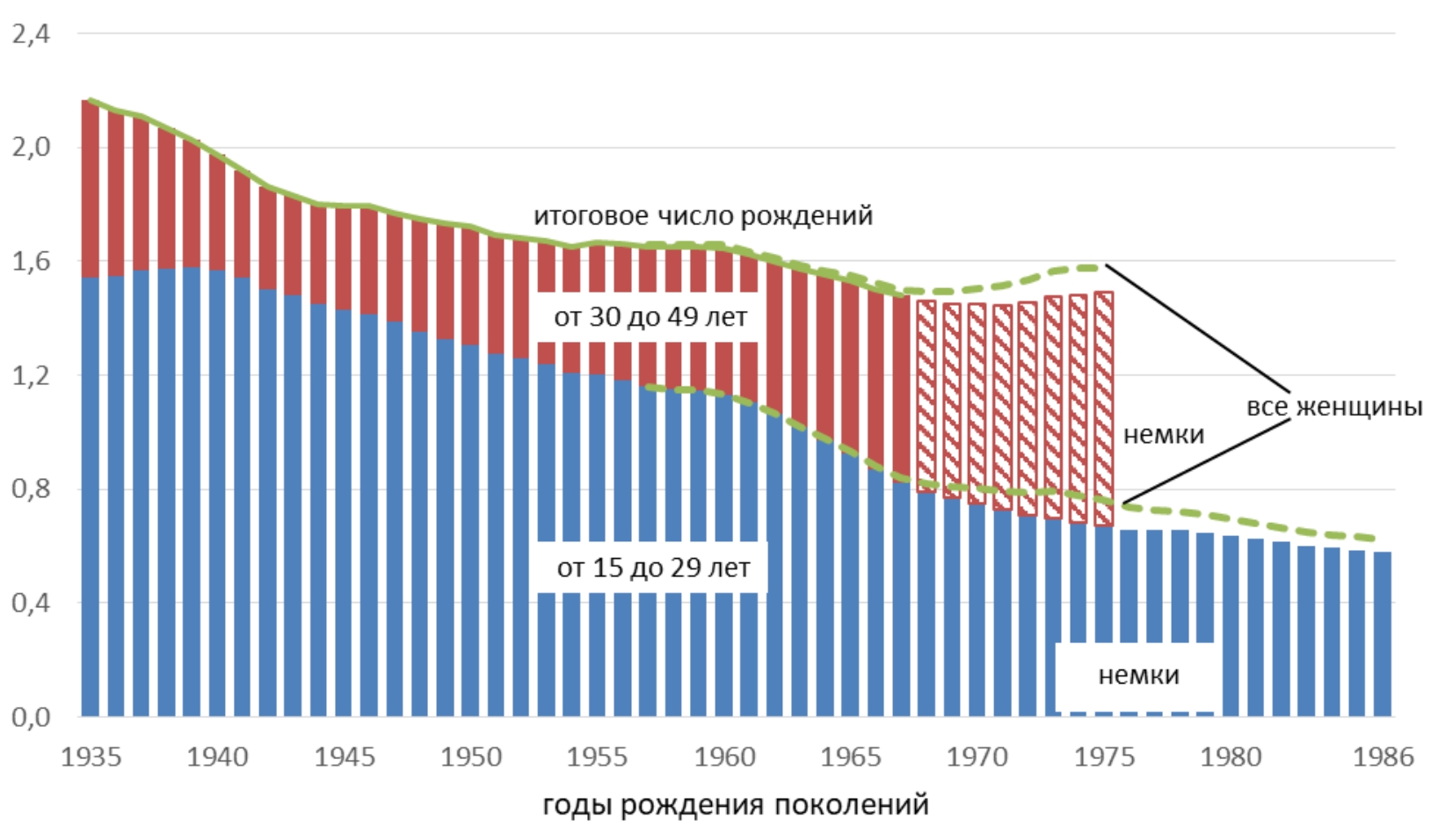

Рисунок 7. Итоговое число рождений на женщину и кумулятивная рождаемость в возрасте до и от 30 лет для немок и для всех женщин, включая иностранок. Реальные поколения, 1935-1986 годы рождения

Источник: Расчеты автора по данным ФСУ Германии за 2016 г.

Каким будет влияние иностранок на рождаемость в Германии в будущем, сказать на настоящий момент чрезвычайно трудно. Очевидно, что оно будет относительно устойчивым, так как доля мигранток в молодых поколениях возросла и продолжает увеличиваться. Сила же этого влияния будет зависеть от множества факторов, в первую очередь, таких как экономические и социально-политические условия в Германии в целом и, в частности, для мигрантов, состав мигрантов по стране происхождения, перспективы 
для пребывания и воссоединения семей в Германии. Что касается резкого подъема КСР иностранок за последние годы, то к нему следует относиться с осторожностью. Целый ряд исследований говорит о том, что рождаемость в первые годы после иммиграции женщин сильно возрастает, а по прошествии нескольких лет снижается [Andersson 2004; Toulemon 2006; Sobotka, Lutz 2011]. В отличие от женщин коренного населения, чья рождаемость является функцией детородного возраста, на рождаемость мигранток влияет в значительной степени их возраст в момент иммиграции. Поэтому необходимы дополнительные наблюдения и более детальный анализ рождаемости мигранток, прибывших в Германию в последние годы.

Исходя из сказанного, в отношении гипотез перспективного расчета могут быть сделаны следующие выводы:

- Краткосрочные предположения о рождаемости условных поколений должны быть в следующем раунде перспективных расчетов скорректированы с учетом роста возрастных и суммарного коэффициентов рождаемости.

- Для кардинального пересмотра долгосрочных гипотез, ориентирующихся на перспективы развития итоговой рождаемости реальных поколений, пока нет оснований. Центральные составляющие репродуктивного поведения реальных поколений, такие как средний возраст матери при рождении первого ребенка и интервалы между рождениями, следуют прежнему тренду. В рождаемости когорт немецких женщин не ожидается устойчивого повышения итогового числа детей.

- Новым и существенным является прекращение роста окончательной бездетности. Это говорит о том, что стабилизация итогового числа детей на уровне 1,6 ребенка на женщину является обоснованным предположением, как минимум, на среднесрочную перспективу.

- Самым труднопредсказуемым фактором остается миграция. Ввиду возросшего влияния миграции на общий уровень деторождения надежность гипотез в целом снижается. Это обусловливает необходимость расширения спектра возможных сценариев будущего развития.

\section{5. ЗАКЛЮЧЕНИЕ}

Целью данной статьи было ознакомить российского читателя с подходами к прогнозным расчетам населения в Германии. Мы рассмотрели задачи, концепцию и особенности методологии официальных перспективных расчетов ФСУ Германии. На примере 13-го координированного перспективного расчета были представлены предположения и дизайн вариантов. Главной целью таких расчетов в Германии является верная оценка средне- и долгосрочных последствий протекающих или назревающих демографических изменений. Каждый новый перспективный расчет представляет собой систему реально возможных вариантов будущего развития. С учетом свойственной будущему неопределенности все принятые гипотезы по рождаемости, смертности и миграции комбинируются между собой в «равноценные» варианты. Чтобы перспективные расчеты могли выполнить свою сигнальную функцию, предположения должны базироваться на верном анализе исходной демографической ситуации и регулярно корректироваться с учетом новых тенденций. 
На примере предположений по рождаемости был описан один из возможных подходов к поиску и обоснованию гипотез. В основе моделирования гипотез рождаемости лежат анализ и экстраполяция возрастных трендов рождаемости, с одной стороны, и предположения об итоговом числе детей реальных поколений, с другой. В перспективе условных поколений рост рождаемости в возрастах от 30 лет замещает снижение деторождения в молодых возрастах. Это обусловливает низкий, но стабильный КСР. В реальных поколениях такой «компенсации» не происходило. С ростом среднего возраста матери при рождении первого ребенка уменьшалась доля многодетных матерей и распространялась окончательная бездетность. В результате снижалось среднее итоговое число детей. Гипотезы об итоговом числе детей на среднесрочную перспективу были обоснованы следующими устойчивыми тенденциями в рождаемости реальных поколений: повышением среднего возраста матери при рождении первого ребенка, ростом доли бездетных женщин, относительно большими и стабильными интервалами между рождениями у одной матери, средним числом детей на мать около 2, которое может, однако, снизиться до 1,9 при дальнейшем «откладывании» первого ребенка. Границы предположений были обозначены параметрами бездетности соответственно в 20 или 25\% и среднего числа детей на мать соответственно 2,0 или 1,9, что дает среднее итоговое число детей на одну женщину 1,6 или 1,4 соответственно.

В заключение мы проанализировали факторы роста рождаемости в 2012-2016 гг. и их значение для гипотез следующего перспективного расчета. Самыми существенными являются изменения в тренде бездетности и рост влияния миграции. Это обусловливает необходимость расширения спектра возможных сценариев будущего.

Работа по поиску предположений никогда не бывает завершена. Новые пути анализа и моделирования гипотез, изменения в динамике самих демографических процессов требуют регулярного пересмотра предположений. За последние годы повысился интерес к результатам на краткосрочную перспективу. Учитывая новые требования, в том числе со стороны Европейской Комиссии, ФСУ Германии в сотрудничестве с Евростатом (статистическим ведомством ЕС) и экспертами из других стран-членов ЕС работает над новыми подходами в области краткосрочных сценариев.

В рамках одной статьи было невозможно охватить все существенные аспекты прогнозирования населения. В частности, остались незатронутыми подходы к предположениям по смертности и миграции, преимущества и недостатки стохастического и сценарного методов моделирования, а также современные аспекты международной дискуссии.

Безусловно, стоящая перед прогностиками задача амбивалентна. Достаточно вспомнить известный афоризм, о том, что «прогнозы - вещь сложная, особенно если они касаются будущего» ${ }^{11}$. Но если мы хотим осознанно воздействовать на будущее, то альтернативы для регулярно актуализируемых долгосрочных перспективных расчетов нет. Одновременно, ответственное отношение к прогнозированию требует транспарентности и

11 Эта меткая тавтология приписывается множеству авторов, в том числе Марку Твену, Нильсу Бору и Уинстону Черчиллю. 
неустанного напоминания пользователю о том, что это лишь попытка приближения будущего, но не само будущее.

\section{БЛАГОДАРНОСТИ}

Автор благодарит Сергея Захарова за предоставленную информацию о прогнозах населения в России и Томаша Соботку за ценные рекомендации по рождаемости женщинмигранток, а также выражает признательность двум анонимным рецензентам за конструктивные замечания, учтенные в данной версии статьи.

\section{ЛИТЕРАТУРА}

Андреев Е.М. (1972). О связи реального и гипотетического поколений // Модели демографических связей. М.: Статистика: 14-39.

Архангельский В.Н., В.В. Елизаров (2016). Демографические прогнозы в современной России: анализ результатов и выбор гипотез // Научные труды Института народнохозяйственного прогнозирования РАН: 521-545.

Захаров С.В. (2017). Потенциал структурных факторов роста рождаемости исчерпан? Часть вторая // Демоскоп Weekly. 733-734. URL: http://demoscope.ru/weekly/2017/0733/tema01.php (дата обращения: 30.04.2018).

Andersson G. (2004). Childbearing after migration: fertility patterns of foreign-born women in Sweden // International Migration Review. 38. 2: 747-775. DOI: 10.1111/j.17477379.2004.tb00216.x

Bowley A.L. (1924). Births and Population of Great Britain // The Journal of the Royal Economic Society. 34: 188-192.

Bujard M., J. Dorbritz, R. Herter-Eschweiler, L. Lux (2015). Das unterschätzte Potenzial der hohen Fallzahlen - Stärken und Limitierungen des Mikrozensus // Zeitschrift für Familienforschung. 3: 343-373.

Cannan E. (1895). The probability of a cessation of the growth of population in England and wales during the next century // The Ecomonic Journal. 5. 20: 505-515.

Frejka T., T. Sobotka (2008). Overview chapter: fertility in Europe: diverse, delayed and below replacement // Demographic Research. 19. 3: 30. DOI:10.4054/Dem-Res.2008.19.3

Keyfitz N. (1972). On future population // Journal of the American Statistical Association. 67/338: 347-363. DOI: 10.1080/01621459.1972.10482386

Bevölkerungsstatistikgesetz (2015). Bevölkerungsstatistikgesetz vom 20. April 2013 (BGBl. I S. 826), das zuletzt durch Artikel 13 des Gesetzes vom 20. November 2015 (BGBl. I S. 2010) geändert worden ist. §5(3).

Luy M., O. Pötzsch (2011). Estimates of the tempo-adjusted total fertility rate in Western and Eastern Germany, 1955-2008 // Comparative Population Studies. 35. 3: 569-604. DOI: 10.4232/10.CPoS-2010-14en

Pötzsch O. (2013). What effects does childbearing postponement have on cohort fertility in western and eastern Germany? // Wirtschaft und Statistik. 2: 87-100. 
Pötzsch O. (2016a). (Un-)Sicherheiten der Bevölkerungsvorausberechnungen - Rückblick auf die koordinierten Bevölkerungsvorausberechnungen für Deutschland zwischen 1998 und 2015 // Wirtschaft und Statistik. 4: 36-53.

Pötzsch O. (2016b). Fertility in German before and after the 2011 census: still no trend reversal in sight // Comparative Population Studies. 41. 1: 87-118. DOI: 10.12765/10.CPoS-201602en

Rürup-Bericht 2003. Bundesministerium für Arbeit und Soziales. URL: http://www.bmas.de/DE/Service/Medien/Publikationen/c318-ruerup-bericht.html (дата обращения: 23.05.2018).

Sobotka T., W. Lutz (2011). Misleading policy messages derived from the period TFR: should. We stop using it? // Comparative Population Studies. 35. 3: 7-664. DOI: 10.4232/10.CPoS2010-15en

Sobotka T., K. Zeman, R. Lesthaeghe, T. Frejka, K. Neels (2011). Postponement and recuperation in cohort fertility: Austria, Germany and Switzerland in a European context // Comparative Population Studies. 36. 2-3: 417-452. DOI: 10.4232/10.CPoS-2011-10en

Sobotka T. (2017). Childlessness in Europe: reconstruction long-term trends among women born in 1900-1972 // Childlessness in Europe: Contexts, Causes, and Consequences / M.

Kreyenfeld, D. Konietzka, eds. Springer Open: 17-56.

Statistisches Bundesamt (2015a). URL:

https://www.destatis.de/EN/FactsFigures/SocietyState/Population/PopulationProjection/Popu lationProjection.html (дата обращения: 23.05.2018).

Statistisches Bundesamt (2015b). Germany's population by 2060 - results of the 13th coordinated population projection. URL:

https://www.destatis.de/EN/Publications/Specialized/Population/GermanyPopulation2060_5 124206159004.pdf?_blob=publicationFile (дата обращения: 23.05.2018).

Statistisches Bundesamt (2017a). Updating the 13th coordinated population projection - base 2015. URL:

https://www.destatis.de/EN/FactsFigures/SocietyState/Population/PopulationProjection/Upda tePopulationProjection.html (дата обращения: 21.12.2017).

Statistisches Bundesamt (2017b). Geburtenabstand zum Geburtstag des vorangegangenen Kindes der Mutter 2015. URL:

https://www.destatis.de/DE/ZahlenFakten/GesellschaftStaat/Bevoelkerung/Geburten/Tabelle n/LebendgeboreneGeburtenabstand.html (дата обращения: 21.12.2017).

Statistisches Bundesamt (2017c). Daten zu Kinderlosigkeit, Geburten und Familien - Ergebnisse des Mikrozensus 2016 - Ausgabe 2017. URL:

https://www.destatis.de/DE/Publikationen/Thematisch/Bevoelkerung/HaushalteMikrozensus/ GeburtentrendsTabellenband5122203169014.pdf?_blob=publicationFile (дата обращения: 23.05.2018).

Schwarz N. (2001). The German microcensus // Schmollers Jahrbuch. 121: 649-654.

te Velde E., D. Habbema, H. Leridon, M. Eijkemans (2012). The effect of postponement if first motherhood on permanent involuntary childlessness and total fertility rate in six European countries since the 1970s // Human Reproduction. 27. 4: 1179-1183. DOI:

10.1093/humrep/der455 
Toulemon L. (2006). Fertility among immigrant women: new data, new approach // Population \& Societies. 400 (April): 1-4. URL: [http://paa2006.princeton.edu/papers/61103] (дата обращения: 23.05.2018).

Whelpton P.K. (1936). An empirical method of calculating future population // The Journal of the American Statistical Association. 31. 195: 457-473.

Willekens F.J. (1990). Demographic forecasting; state-of-the-art and research needs // Emerging issues in demographic research / C.A. Hazeu, G.A.B. Frinking, eds. 9-76.

zur Nieden F., B. Sommer, O. Pötzsch (2016). Recent Refugee influx and migration assumptions in Germany - public debate and opportunities for projection makers // Joint Eurostat/UNECE Work Session on Demographic Projections. 18-20 April 2016. URL:

https://www.unece.org/index.php?id=41283 (дата обращения: 23.05.2018). 


\title{
POPULATION PROJECTIONS IN GERMANY
}

\section{OLGA PÖTZSCH}

\begin{abstract}
Purposeful social and economic policy is unthinkable without any idea of the future development of the population and its structure. The gradual changes of demographic processes allow us to make population projections, which serve as a kind of compass. Their results show how population size and structure will change given certain hypotheses concerning the development of fertility, mortality and migration. The impact of these demographic processes on the population manifests itself in full only after a few decades. Therefore, projections with a long-term horizon are of particular interest.
\end{abstract}

This article presents the official population projections provided by the German Federal Statistical Office. These projections are based on the widely used cohort-component method and deterministic approach, yet possess a number of distinctive features: Both the interpretation of the goals and results, as well as some details of the methodology and design of the scenarios as a system of equivalent future options, are different from those currently accepted in Russia. Using fertility assumptions of the 13th population projection as an example, the article introduces one of the possible approaches to modeling hypotheses. It focuses on the justification of assumptions based on the cohort analysis and the characteristics of reproductive behavior of women cohorts. In conclusion, the hypotheses about completed fertility based on data until 2013 are critically analyzed, taking into account the rise in fertility in recent years in Germany. An analysis of the factors that accompany this recovery allows us to assess their potential for the future development of cohort fertility.

Key words: population projections, cohort-component-method, fertility assumptions, mean age of childbearing, postponement and recuperation, cohorts, total fertility rate, competed fertility.

Olga Pötzsch (olga.poetzsch@destatis.de), Statistisches Bundesamt (Destatis), Germany.

DATE RECEIVED : DECEMBER 2017.

\section{REFERENCES}

Andersson G. (2004). Childbearing after migration: fertility patterns of foreign-born women in Sweden // International Migration Review. 38(2): 747-775. DOI: 10.1111/j.1747-

7379.2004.tb00216.x

Andreev E.M. (1972). O svyazi real'nogo i gipoteticheskogo pokoleniy [On the connection between the real and hypothetical cohorts] // Modeli demograficheskikh svyazey [Models of demographic interrelations]. Moscow: Statistika: 14-39.

Arhangelskiy V.N., V.V. Elizarov (2016). Demograficheskie prognozy v sovremennoy Rossii: analiz rezul'tatov i vybor gipotez [Demographic forecasts in modern Russia: analysis of the results and choice of hypotheses] // Nauchnyye trudy Instituta narodnokhozyaystvennogo prognozirovaniya RAN [Scientific works of the Institute for Economic Forecasting, RAS]: 521-545.

Bevölkerungsstatistikgesetz (2015). Bevölkerungsstatistikgesetz vom 20. April 2013 (BGBl. I S. 826), das zuletzt durch Artikel 13 des Gesetzes vom 20. November 2015 (BGBl. I S. 2010) geändert worden ist. §5(3).

Bowley A.L. (1924). Births and population of Great Britain // The Journal of the Royal Economic Society. 34: 188-192.

Bujard M., J. Dorbritz, R. Herter-Eschweiler, L. Lux (2015). Das unterschätzte Potenzial der hohen Fallzahlen - Stärken und Limitierungen des Mikrozensus // Zeitschrift für Familienforschung. 3: 343-373. 
Cannan E. (1895). The probability of a cessation of the growth of population in England and wales during the next century // The Ecomonic Journal. 5(20): 505-515.

Frejka T., T. Sobotka (2008). Overview chapter: fertility in Europe: diverse, delayed and below replacement // Demographic Research. 19(3): 30. DOI:10.4054/Dem-Res.2008.19.3

Keyfitz N. (1972). On future population // Journal of the American Statistical Association. 67/338: 347-363. DOI: 10.1080/01621459.1972.10482386

Luy M., O. Pötzsch (2011). Estimates of the tempo-adjusted total fertility rate in Western and Eastern Germany, 1955-2008 // Comparative Population Studies. 35(3): 569-604. DOI: 10.4232/10.CPoS-2010-14en

Pötzsch O. (2013). What effects does childbearing postponement have on cohort fertility in western and eastern Germany? // Wirtschaft und Statistik. 2: 87-100.

Pötzsch O. (2016a). (Un-)Sicherheiten der Bevölkerungsvorausberechnungen - Rückblick auf die koordinierten Bevölkerungsvorausberechnungen für Deutschland zwischen 1998 und 2015 // Wirtschaft und Statistik. 4: 36-53.

Pötzsch O. (2016b). Fertility in German before and after the 2011 census: still no trend reversal in sight // Comparative Population Studies. 41(1): 87-118. DOI: 10.12765/10.CPoS-201602en

Rürup-Bericht 2003. Bundesministerium für Arbeit und Soziales. URL: http://www.bmas.de/DE/Service/Medien/Publikationen/c318-ruerup-bericht.html (accessed: 23.05.2018).

Schwarz N. (2001). The German microcensus // Schmollers Jahrbuch. 121: 649-654.

Sobotka T. (2017). Childlessness in Europe: reconstruction long-term trends among women born in 1900-1972 // Childlessness in Europe: Contexts, Causes, and Consequences / M.

Kreyenfeld, D. Konietzka, eds. Springer Open: 17-56.

Sobotka T., K. Zeman, R. Lesthaeghe, T. Frejka, K. Neels (2011). Postponement and recuperation in cohort fertility: Austria, Germany and Switzerland in a European context // Comparative Population Studies. 36(2-3): 417-452. DOI: 10.4232/10.CPoS-2011-10en

Sobotka T., W. Lutz (2011). Misleading policy messages derived from the period TFR: should we stop using it? // Comparative Population Studies. 35(3): 7-664. DOI: 10.4232/10.CPoS2010-15en

Statistisches Bundesamt (2015a). URL: https://www.destatis.de/EN/FactsFigures/SocietyState/Population/PopulationProjection/Popu lationProjection.html (accessed: 23.05.2018).

Statistisches Bundesamt (2015b). Germany's population by 2060 - results of the 13th coordinated population projection. URL:

https://www.destatis.de/EN/Publications/Specialized/Population/GermanyPopulation2060_5 124206159004.pdf?_blob=publicationFile (accessed: 23.05.2018).

Statistisches Bundesamt (2017a). Updating the 13th coordinated population projection - base 2015. URL:

https://www.destatis.de/EN/FactsFigures/SocietyState/Population/PopulationProjection/Upda tePopulationProjection.html (accessed: 21.12.2017).

Statistisches Bundesamt (2017b). Geburtenabstand zum Geburtstag des vorangegangenen Kindes der Mutter 2015. URL:

https://www.destatis.de/DE/ZahlenFakten/GesellschaftStaat/Bevoelkerung/Geburten/Tabelle n/LebendgeboreneGeburtenabstand.html (accessed: 21.12.2017). 
Statistisches Bundesamt (2017c). Daten zu Kinderlosigkeit, Geburten und Familien - Ergebnisse des Mikrozensus 2016 - Ausgabe 2017. URL:

https://www.destatis.de/DE/Publikationen/Thematisch/Bevoelkerung/HaushalteMikrozensus/ GeburtentrendsTabellenband5122203169014.pdf?_blob=publicationFile (accessed: 23.05.2018).

te Velde E., D. Habbema, H. Leridon, M. Eijkemans (2012). The effect of postponement if first motherhood on permanent involuntary childlessness and total fertility rate in six European countries since the 1970s // Human Reproduction. 27(4): 1179-1183. DOI: 10.1093/humrep/der455.

Toulemon L. (2006). Fertility among immigrant women: new data, new approach // Population \& Societies. 400 (April): 1-4. URL: http://paa2006.princeton.edu/papers/61103 (accessed: 23.05.2018).

Whelpton P.K. (1936). An empirical method of calculating future population // The Journal of the American Statistical Association. 31(195): 457-473.

Willekens F.J. (1990). Demographic forecasting; state-of-the-art and research needs / C.A. Hazeu, G.A.B. Frinking, eds. Emerging issues in demographic research: 9-76.

Zakharov S.V. (2017). Potentsial strukturnykh faktorov rosta rozhdaemosti ischerpan? Chast' vtoraya [The potential of structural factors of fertility growth is exhausted? Part two] // Demoscope Weekly. 733-734. URL: http://demoscope.ru/weekly/2017/0733/tema01.php (accessed: 30.04.2018).

zur Nieden F., B. Sommer, O. Pötzsch (2016). Recent Refugee influx and migration assumptions in Germany - public debate and opportunities for projection makers // Joint Eurostat/UNECE Work Session on Demographic Projections. 18-20 April 2016. URL: https://www.unece.org/index.php?id=41283 (accessed: 23.05.2018). 